\title{
The AVOID programme's new simulations of the global benefits of stringent climate change mitigation
}

Article

Accepted Version

Warren, R., Lowe, J. A., Arnell, N., Hope, C., Berry, P., Brown, S., Gambhir, A., Gosling, S. N., Nicholls, R. J., O'Hanley, J., Osborn, T. J., Osborne, T., Price, J., Raper, S. C. B., Rose, G. and Vanderwal, J. (2013) The AVOID programme's new simulations of the global benefits of stringent climate change mitigation. Climatic Change, 120 (1-2). pp. 55-70. ISSN 01650009 doi: https://doi.org/10.1007/s10584-013-0814-4 Available at https://centaur.reading.ac.uk/33370/

It is advisable to refer to the publisher's version if you intend to cite from the work. See Guidance on citing.

Published version at: http://dx.doi.org/10.1007/s10584-013-0814-4

To link to this article DOI: http://dx.doi.org/10.1007/s10584-013-0814-4

Publisher: Springer

All outputs in CentAUR are protected by Intellectual Property Rights law, including copyright law. Copyright and IPR is retained by the creators or other copyright holders. Terms and conditions for use of this material are defined in the End User Agreement. 


\section{CentAUR}

Central Archive at the University of Reading

Reading's research outputs online 
1 Title: The AVOID programme's new simulations of the global benefits of stringent

\section{climate change mitigation}

Authors: Warren, R., Lowe. J. A., Arnell, N.W., Hope, C, Berry, P., Brown, S., Gambhir, A., Gosling, S.N., Nicholls, R.J., O’Hanley, J., Osborn, T.J., Osborne, T., Price, J., Raper, S.C.B., Rose, G. Vanderwal, J.

Abstract Quantitative simulations of the global-scale benefits of climate change mitigation are presented, using a harmonised, self-consistent approach based on a single set of climate change scenarios. The approach draws on a synthesis of output from both physically-based and economics-based models, and incorporates uncertainty analyses. Previous studies have projected global and regional climate change and its impacts over the $21^{\text {st }}$ century but have generally focused on analysis of business-as-usual scenarios, with no explicit mitigation policy included. This study finds that both the economics-based and physically-based models indicate that early, stringent mitigation would avoid a large proportion of the impacts of climate change projected for the 2080s. However, it also shows that not all the impacts can now be avoided, so that adaptation would also therefore be needed to avoid some of the potential damage. Delay in mitigation substantially reduces the percentage of impacts that can be avoided, providing strong new quantitative evidence for the need for stringent and prompt global mitigation action on greenhouse gas emissions, combined with effective adaptation, if large, widespread climate change impacts are to be avoided. Energy technology models suggest that such stringent and prompt mitigation action is technologically feasible, although the estimated costs vary depending on the specific modelling approach and assumptions.

\section{Main Text:}

Many previous studies have used physically-based models to project global and regional climate change and its impacts over the $21^{\text {st }}$ century (Solomon et al. 2007) but have generally focused on analysis of business-as-usual scenarios, with no explicit mitigation policy included. The few exceptions (Ciscar et al. 2011) have tended to provide limited coverage of sectors or regions. 
A new UK stakeholder-led program - Avoiding Dangerous Climate Change (AVOID) - has now produced quantified, integrated, physically- and economics-based modelling information about the global-scale benefits of global climate change mitigation. A key focus is the climate changes and impacts that can be avoided by stringent action to reduce anthropogenic emissions of greenhouse gases. An important aspect of the approach is the use of two complementary probabilistic modelling approaches. The first is the creation of a link between probabilistic climate change projection and complex physically based climate change impacts models. The second is the use a probabilistic integrated model to simulate aggregate economic impacts of climate change.

The AVOID program addresses three questions posed by stakeholders from UK government departments: (i) What large-scale climate changes (which are often undesirable and sometimes considered dangerous) are likely to be triggered by different amounts of future warming? (ii) What emissions and development pathways can minimize the undesirable impacts of climate change? (iii) Are these emissions pathways economically and technologically feasible? The results summarised in this paper present the program's initial steps towards answering these questions.

Alternative global emission pathways for the $21^{\text {st }}$ century, including two 'business as usual' scenarios $\mathrm{A} 1 \mathrm{~B}$ and $\mathrm{A} 1 \mathrm{FI}$, and several mitigation scenarios, are used to drive a simple climate model that estimates resultant global-mean warming. The mitigation pathways initially follow a business as usual scenario, SRES A1B (Nakicenovich et al. 2000) and then transition over seven years to zero emissions growth. The rate of reduction in emissions growth is then applied beyond the peak until the emissions reach a long term rate of reduction. This long term reduction rate is applied until emissions reach a "floor" value, which can be considered as a point beyond which it is difficult to mitigate, such as may be associated with a need to maintain food supply through application of fertilisers leading to emissions of $\mathrm{N}_{2} \mathrm{O}$. Variations in the year in which emissions peak globally (2016 or 2030), the long-term rate of emission reduction ( 1 to 5\%/yr), and a range of different emission floors (from 0 to 17 $\mathrm{GtCO}_{2} \mathrm{e} / \mathrm{yr}$ ) provide 150 alternative multi-gas mitigation pathways. Emissions of $\mathrm{CO}_{2}, \mathrm{CH}_{4}$ and $\mathrm{N}_{2} \mathrm{O}$ are specified along with more minor constituents and aerosol emissions. Six scenarios are selected for analysis of avoided regional climate change and impacts (Table 1). Although our mitigation scenarios start from the SRES A1B scenario it is acceptable to compare the impacts avoided with both SRES A1B and SRES A1FI because for the first few 
decades of the $21^{\text {st }}$ century, when mitigation action is initiated in our experiments, there is little difference in the climate response of the two business as usual scenarios.

Table 1. The AVOID baseline and mitigation scenarios.

\begin{tabular}{|l|l|l|c|c|}
\hline Name & Type & $\begin{array}{l}\text { Year global } \\
\text { emissions peak }\end{array}$ & $\begin{array}{c}\text { Rate of subsequent } \\
\text { emission reduction \%/yr }\end{array}$ & Emissions floor \\
\hline A1FI & Baseline & N/A & None & N/A \\
\hline A1B & Baseline & 2050 & None & N/A \\
\hline 2016 r2H & Mitigation & 2016 & 2 & High \\
\hline 2016r4L & Mitigation & 2016 & 4 & Low \\
\hline 2016r5L & Mitigation & 2016 & 5 & High \\
\hline 2030 r2H & Mitigation & 2030 & 2 & Low \\
\hline 2030r5L & Mitigation & 2030 & 5 &
\end{tabular}

For our estimation of physically based impacts this study uses the simple climate model MAGICC (Wigley \& Raper, 2001) which was extensively used by the Intergovernmental Panel on Climate Change (IPCC) (Hougton et al. 2001), and is capable of emulating globalmean warming from more complex models. This is necessary because the sample of more complex GCMs that were available and which directly used mitigation scenarios was still very limited when the impact calculations were carried out (e.g. Johns et al., 2011 for an early example). Whilst the CMIP5 model intercomparison is providing more GCM simulations for a mitigation pathway, even now these are available only for a very limited number of mitigation cases, typically only E1 (Lowe et al., 2009a) and RCP2.6 (Moss et al. 2010). For our study we require a wider range of emission pathways so that we can compare the relative effects of emission peak year and long-term emission reduction rate on climate impacts. Thus, we have used the simple climate model approach, combined where appropriate with spatial pattern scaling, as the only viable approach to covering the scenarios of interest. Uncertainty in climate response was included for three key MAGICC parameters, the climate sensitivity (defined as the equilibrium global mean temperature increase for a doubling of atmospheric $\mathrm{CO} 2$ ), the ocean mixing rate (that determines how quickly the warming at the surface is diffused throughout the ocean), and a climate-carbon cycle feedback amplification 
factor (that amplifies the temperature dependent climate-carbon cycle feedback in MAGICC). The precise details are described in Lowe et al. (2009b). These uncertainties are propagated through to the impacts analysis, and a suite of physically-based impacts models which characterise impacts in a range of metrics. Uncertainties within the physical impacts models themselves are, in general, not considered within the study.

The study's projections of global temperature rise are consistent with the IPCC's projected global annual warming in baseline scenarios SRES A1B of $1.7-4.4^{\circ} \mathrm{C}$ above 1990 levels by the end of the century (Solomon et al. 2007) (i.e., 2.2-4.9 ${ }^{\circ}$ Cabove pre-industrial levels). The median warming in the A1B business as usual scenarios is $4^{\circ} \mathrm{C}$ above pre-industrial levels (10-90 percentile range is $3.1-5.5^{\circ} \mathrm{C}$ above pre-industrial levels). In contrast, stringent mitigation that causes global annual emissions to peak in 2016 and decline at 5\% annually thereafter produces a 55\% chance of limiting warming to $2^{\circ} \mathrm{C}$ above pre-industrial levels. This mitigation also reduces the chance of global warming reaching $3^{\circ} \mathrm{C}$ above pre-industrial levels from 19 in 20 in the business as usual scenario to 1 in 20 with stringent mitigation. Scenarios in which global annual emissions peak in 2030 are unable to deliver a 50\% chance of limiting annual global mean temperature change to $2^{\circ} \mathrm{C}$ above pre-industrial levels, although they do provide a greater than evens chance (66\% to $75 \%$ ) that warming will remain below $3^{\circ} \mathrm{C}$ and reduce the chance of a $4^{\circ} \mathrm{C}$ rise to about $3 \%$. Figure 1a summarises these outcomes. A detailed analysis of the relationship between peaking date for global emissions, subsequent emission reduction rates, and levels of emissions in 2050 may be found in Huntingford et al. (2012).

Projections for specific impact sectors were made using spatially-explicit process-based global physical impacts models, covering water resources, river and coastal flood risk, wetland loss, terrestrial biodiversity, crop suitability and productivity, and heating and cooling demands (Arnell et al 2013, Warren et al in press). A direct comparison is made between the levels of impacts in the presence and absence of action to reduce emissions of greenhouse gas emissions. The models include the influence of socioeconomic factors such as population upon impacts. These factors are held constant across all scenarios so that the effect of climate change is isolated. 
124 All impacts projections were run with spatially-explicit climate scenarios produced by pattern-scaling climate model output to match the changes in global mean temperature as simulated by MAGICC under the different emissions pathways, and with socio-economic impact metrics assuming that population and economic growth follow either the SRES A1B or SRES A1FI socio-economic scenarios (see Arnell et al., 2013, for more details of the hydrological, crop, coastal and temperature-based indicators). Pattern-scaling (Warren et al., 2012) has a number of advantages, including that climate change projections can be constructed for (e.g. mitigation) scenarios that have not been simulated by the GCMs, but also some limitations, principally that it assumes a linear change in the amplitude of the regional pattern of climate as the global-mean temperature increases. In some instances, GCMs exhibit more complex behaviour, which is not captured by the pattern-scaling approach used here. This method has been shown to provide an "acceptable" emulation of the GCM responses for the types of scenario studied here, given the other large uncertainties in estimation of regional climate changes. The water resources and river flooding indicators were based on river flows simulated using Mac-PDM.09 (Gosling \& Arnell, 2011). Changes in exposure to water resources stress is characterised by the total numbers of people living in watersheds with less than $1000 \mathrm{~m}^{3} /$ capita/year in the 1961-1990 baseline experiencing a significant decrease or increase in average annual runoff, where a significant change in runoff is greater than the standard deviation in average annual runoff due to multi-decadal variability. Change in exposure to river flooding is characterised by the numbers of people living in flood-prone areas where the return period of the baseline 20-year flood either doubles or halves due to climate change. In different parts of the world, exposure to both water stress and river flooding may increase or decrease in response to climate change. Change in coastal flood risk and coastal wetland extent were calculated using DIVA 2.0.4 (Hinkel \& Klein, 2009), which combines the effect of natural land movement and sea level rise. Coastal flood risk is characterised by the average annual number of people flooded in coastal floods, and it is assumed that the level of coastal flood protection increases as population density and wealth in flood-prone areas increases, and also as sea level rises; some adaptation is therefore assumed. The effect of climate change on the suitability of land for cropping is characterised by the area of cropland over which Ramankutty et al.'s (2009) crop suitability index changes by more than 5\%; the index combines climate suitability (defined by rainfall, temperature and evaporation) and crop suitability (based on soil carbon content and $\mathrm{pH}$ ). Both improvements and decreases in crop suitability are simulated. The productivity of spring wheat and soybean was estimated using the GLAM model (Challinor et al., 2004), 
which simulates crop productivity based on climate, $\mathrm{CO}_{2}$ concentration and soil characteristics; some adaptation is incorporated here, as it is assumed that the variety with the greatest yield under the simulated climate is planted. Changes in heating and cooling requirements are represented by changes in regional population-weighted heating and cooling degree days (using $18^{\circ} \mathrm{C}$ as the temperature threshold for both heating and cooling). A global analysis of impacts on biodiversity (Warren et al. in press) provides the potential climatic range changes for 48,786 animal and plant species across the globe under the AVOID scenarios, using MaxEnt (Elith et al .2010) $80 \%$ of these species have climatic ranges in excess of $30,000 \mathrm{~km}^{2}$, hence these climatic range losses would affect ecosystem services across large areas. A realistic level of species dispersal (natural adaptation by biodiversity) is assumed to take place. Uncertainties within the physical impacts models themselves are mostly not considered within the study. Models simulate responses to climate change that are beneficial as well as those which are not. Where climate change has a detrimental impact, the avoided impacts are defined as positive in sign; where climate change has a beneficial impact, the avoided impacts are defined as negative in sign.

The second approach to estimating impacts used the simple integrated model PAGE2002 (Policy Analysis for the Greenhouse Effect: Hope, 2008), which simulates the radiative forcing and greenhouse warming resulting from the selected six emission scenarios, and further estimates the economic damage caused by warming to market and non-market sectors using parameters estimated from the literature. The climate model within PAGE2002 is simpler than the MAGICC plus pattern-scaling approach used for the physical impact modelling exercise but it is nevertheless still able to credibly sample the uncertainty in the transient climate response and the long-term response of surface temperatures for the scenarios of interest. The differences in damages between the SRES A1B baseline and policy scenarios are compared to produce estimates of the benefits of reduced carbon emissions. Equity weighting of the damages can be introduced into the calculations to reflect the wide disparity in incomes between the developed and developing worlds. Parameters linking emissions to climate change and linking climate change to damages are incorporated as probability distributions, thus enabling a probabilistic analysis to take place. The model also includes damages that might result from abrupt changes in the Earth's response to greenhouse warming (Hope, 2008). 
The impacts under the different emissions scenarios are simulated using an integrated assessment model, PAGE2002, which estimates impacts in economic terms, and a suite of physically-based impacts models which characterise impacts in a range of metrics. The combination of the two contrasting modelling approaches (physical and integrated) allows investigation of the robustness of outputs to the use of very different modelling approaches.

Table 2 summarises the indicators used and explains whether they are used show benefits or losses in response to climate change.

Table 2. Indicators used in the study.

\begin{tabular}{|c|c|c|}
\hline Indicator & Metric & Sign adopted in Figure $2 \mathrm{a}, \mathrm{b}$ \\
\hline $\begin{array}{l}\text { Total economic } \\
\text { damages }\end{array}$ & & $\begin{array}{l}\text { PAGE simulates disbenefits of } \\
\text { climate change, the avoided } \\
\text { damage is a positive number }\end{array}$ \\
\hline $\begin{array}{l}\text { No. of species losing } \\
\text { more than half their } \\
\text { current climatic range }\end{array}$ & Count of species & $\begin{array}{l}\text { The number of species protected } \\
\text { due to mitigation is shown as a } \\
\text { positive number }\end{array}$ \\
\hline $\begin{array}{l}\text { Improvement in crop } \\
\text { suitability }\end{array}$ & Area of cropland & $\begin{array}{l}\text { Since increased suitability is a } \\
\text { benefit which mitigation reduces, } \\
\text { the avoided impacts are negative }\end{array}$ \\
\hline $\begin{array}{l}\text { Decrease in crop } \\
\text { suitability }\end{array}$ & Area of cropland & $\begin{array}{l}\text { Since decreased suitability is a loss } \\
\text { which mitigation reduces, the } \\
\text { avoided impacts are positive }\end{array}$ \\
\hline $\begin{array}{l}\text { Exposure to increased } \\
\text { water stress }\end{array}$ & $\begin{array}{l}\text { Number of people } \\
\text { living in water- } \\
\text { stressed watersheds }\end{array}$ & $\begin{array}{l}\text { Since increased exposure is a loss } \\
\text { which mitigation reduces, the } \\
\text { avoided impacts are positive }\end{array}$ \\
\hline $\begin{array}{l}\text { Exposure to decreased } \\
\text { water stress }\end{array}$ & $\begin{array}{l}\text { Number of people } \\
\text { living in water- } \\
\text { stressed watersheds }\end{array}$ & $\begin{array}{l}\text { Since decreased exposure is a } \\
\text { benefit which mitigation reduces, } \\
\text { the avoided impacts are negative }\end{array}$ \\
\hline $\begin{array}{l}\text { Exposure to increased } \\
\text { river flood frequency }\end{array}$ & $\begin{array}{l}\text { Number of people } \\
\text { living in river } \\
\text { floodplains }\end{array}$ & $\begin{array}{l}\text { Since increased exposure is a loss } \\
\text { which mitigation reduces, the } \\
\text { avoided impacts are positive }\end{array}$ \\
\hline
\end{tabular}




\begin{tabular}{|c|c|c|}
\hline $\begin{array}{l}\text { Exposure to decreased } \\
\text { river flood frequency }\end{array}$ & $\begin{array}{l}\text { Number of people } \\
\text { living in river } \\
\text { floodplains }\end{array}$ & $\begin{array}{l}\text { Since decreased exposure is a } \\
\text { benefit which mitigation reduces, } \\
\text { the avoided impacts are negative }\end{array}$ \\
\hline $\begin{array}{l}\text { Change in people } \\
\text { exposed to coastal } \\
\text { flood }\end{array}$ & $\begin{array}{l}\text { Average annual } \\
\text { number of people } \\
\text { flooded in coastal } \\
\text { storms }\end{array}$ & $\begin{array}{l}\text { Sea level only rises in response to } \\
\text { climate change, so these changes } \\
\text { are all losses which mitigation } \\
\text { reduces, so the avoided impacts } \\
\text { are positive }\end{array}$ \\
\hline $\begin{array}{l}\text { Change in coastal } \\
\text { wetland }\end{array}$ & $\begin{array}{l}\text { Area of coastal } \\
\text { wetland }\end{array}$ & $\begin{array}{l}\text { Sea level only rises in response to } \\
\text { climate change, so these changes } \\
\text { are all losses which mitigation } \\
\text { reduces, so the avoided impacts } \\
\text { are positive }\end{array}$ \\
\hline $\begin{array}{l}\text { Change in heating } \\
\text { degree days }\end{array}$ & $\begin{array}{l}\text { Population-weighted } \\
\text { heating degree day } \\
\text { total }\end{array}$ & $\begin{array}{l}\text { Climate change generally } \\
\text { increases regional temperatures so } \\
\text { that there are fewer days below a } \\
\text { heating threshold. This is a benefit } \\
\text { which mitigation reduces, so the } \\
\text { avoided impacts are negative }\end{array}$ \\
\hline $\begin{array}{l}\text { Change in cooling } \\
\text { degree days }\end{array}$ & $\begin{array}{l}\text { Population-weighted } \\
\text { cooling degree day } \\
\text { total }\end{array}$ & $\begin{array}{l}\text { Climate change generally } \\
\text { increases regional temperatures so } \\
\text { that there are more days above a } \\
\text { heating threshold. This is a loss } \\
\text { which mitigation reduces, so the } \\
\text { avoided impacts are positive }\end{array}$ \\
\hline
\end{tabular}

Fig 2a combines output from the PAGE integrated assessment model with those from the physically based models. In particular, the figure shows the impacts avoided in the mitigation scenarios relative to the A1B baseline scenario impacts, expressed as a percentage. Solid bars represent the case average outcome from driving the with the median global climate change outcome from the MAGICC4.1 model combined with the seven alternative patterns of regional downscaling. Note that where climate change causes losses, the avoided impacts 
are shown as positive (red). Where climate change has a beneficial effect, the avoided impacts are shown as negative (blue). Table 2 details which indicators refer to benefits and losses. Overall, the positive benefits of mitigation (red bars in Fig 2a) greatly outweigh the negatives (blue bars in Fig 2a). Further, for past-peak emission reduction rates of 2-5\%, avoided impacts in physical and economic terms in the $21^{\text {st }}$ century are larger for earlier peaking dates (in the range 2016-2030) irrespective of the subsequent emission reduction rate. Both red bars (referring to an emission peaking date of 2016 and subsequent emission reduction at 5\% annually) and pink bars (referring to an emission peaking date of 2016 and subsequent emission reduction at only $2 \%$ annually) produce a larger proportion of avoided impacts than do the orange bars (referring to an emission peaking date of 2030 and subsequent emission reduction at 5\% annually thereafter). Hence, fewer impacts can be avoided (in either physical or economic terms) when global emissions do not peak until 2030, even if emissions are reduced at 5\% thereafter, than if emissions peak in 2016 and are reduced at $2 \%$ annually thereafter. The finding of a tradeoff between emission reduction rate and the date at which global emission peak reflects the relatively fixed relationship between total cumulative $\mathrm{CO}_{2}$ emissions and peak temperature change.

In some individual sectors or regions, avoided physical impacts can be reduced by as much as $70 \%$ by 2100 , whilst in other regions or sectors, only $15 \%$ of the impacts may still be avoided. Many populated areas are projected to experience increased exposure to fluvial flood risk in the business as usual scenario by 2100 , and these risks are reduced by some $60 \%$ with mitigation. A small percentage of world population is actually projected to experience slightly less exposure to fluvial flood risk in the business as usual scenario than in the mitigation scenario. Avoided impacts in sectors impacted by sea level rise tend to be smaller, owing to the slow response of sea level rise to changes in radiative forcing. For sea level rise projections, only a single global circulation model (HadCM3) was used, which provided projections of a rise $47.3 \mathrm{~cm}$ for A1B by the end of the century, which reduced to $30.9 \mathrm{~cm}$ under the most stringent mitigation scenario. However, for many of the impact categories studied, $30-50 \%$ of the impacts are avoided by 2100 relative to the A1B baseline case. Relative to an A1FI baseline case, avoided impacts are larger, ranging from 30-80\%, compared to $20-70 \%$ with the A1B baseline (Figs. 2a,b). 
Fig $2 \mathrm{a}$ also shows error bars representing uncertainty in the estimates of avoided impacts. In the case of the physical impacts models, uncertainty analysis is largely based on uncertainties in climate projection, focusing on uncertainties in the differing regional patterns of change produced when downscaling using different GCM patterns. This is justified because our probabilistic analysis suggests that the contribution to total uncertainty in many impacts from local pattern tends to dominate over the uncertainty from the global response and which is associated with, for instance, the uncertainty in the transient climate response. Seven climate models from the CMIP3 model set were used. The models (HadCM3, HadGEM1, ECHAM5, IPSL_CM4, CCSM3.1 (T47), CGCM3.1 (T63) and CSIRO_MK3.0) span the broad range of changes simulated under the full CMIP3 model set (Meehl et al. 2007), and provide an indication of the range in possible future climates. At the time of writing, studies such as the 'AgMIP' (www.agmip.org) are now producing estimates of the uncertainties inherent in impacts modelling, Further work is required to understand how to correctly combine the uncertainty in transient climate response with local pattern uncertainty, and also to incorporate the outcomes of these ongoing studies of uncertainty within impact model simulations.

Figure 2a also shows that if global emissions peak in 2016, around one half of the aggregate economic impacts can be avoided by the 2080s, but if mitigation is delayed so that emissions peak in 2030, only around a third of the impacts can be avoided. This is the case regardless of whether or not equity weightings are used in the PAGE2002 model. It should be noted that similar trends in terms of the dependence of reduced avoided impacts on the timing of mitigation are produced by the physical impacts models and the PAGE2002 modelling approach (Fig 2a). Uncertainty analysis in the integrated modelling approach is necessarily different from that of the physical modelling approach, as in the case of PAGE the probabilistic analysis synthesises uncertainties in climate projection and damage estimation into a single analysis, allowing the production of $10 \%, 50 \%$, and $90 \%$ outcomes incorporating several aspects of uncertainty, and it is these $10 \%$ and $90 \%$ outcomes which comprise the error bars.

Hence these projections demonstrate that early, stringent mitigation can avoid a large proportion of the impacts of climate change that are projected to occur during the second half of the $21^{\text {st }}$ century, irrespective of whether impacts are measured in physical or economic terms. 
The question then arises as to how large are these physical and economic impacts. Figures 3a, $b$ show probability distributions of aggregate economic impacts in the A1B baseline scenario estimated by the PAGE model, detailing the inclusion or otherwise of equity weighting, which show mean estimates of US\$12.6 trillion (8.2 trillion) of weighted (unweighted) annual aggregate damage in the 2080s, with a $10-90 \%$ range of US\$4-24 trillion (3 -15 trillion). Warren et al. (in press) estimate under the A1B scenario, $57 \pm 6 \% \%$ of plants and $34 \pm 7 \%$ of animals will lose more than half their climatic range by the $2080 \mathrm{~s}$. Detailed physical impacts modelling results presented elsewhere (Arnell et al 2013), also show that the estimated impacts in 2100 under the A1B and A1FI baselines are large. Examples of estimated global scale impacts in 2100 under the A1FI (A1B) scenario using the HadCM3 regional downscaling pattern are: 60\% (38\%) decline in spring wheat productivity; $68 \%(46 \%)$ decline in soybean productivity; $35 \%(32 \%)$ decline in coastal wetland extent; $64 \%(56 \%)$ cropland with decreased crop suitability and 12\% (14\%) with increasing suitability; $16 \%(13 \%)$ of global population with increased exposure to water stress; $65 \%$ $(58 \%)$ of the flood-prone population is exposed to greater flood risk; $125 \%$ (92\%) increase in cooling energy demand and 55\%(42\%) decrease in heating energy demand. However, like many other studies, this one finds large uncertainties in the projections of precise values of avoided impacts, larger, in fact, than the differences between the various mitigation scenarios considered. This is not surprising since the various GCMs produce differing representations of regional climate change. However, what is significant for policy is that the avoided impacts are likely to be large (see Figures 2,3 ) regardless of these uncertainties. The study thus addresses the need to make mitigation decisions against a backdrop of uncertainty in climate projections, by identifying a more robust indicator of mitigation benefits in terms of the percentage of impacts avoided by mitigating. Hence, the projections indicate that the avoided impacts are large and spatially extensive. Nonetheless, adaptation planners still need to prepare for a wide range of possible outcomes in terms of the residual impacts after mitigation has been accounted for.

The results from the global biodiversity analysis here were consistent with a separate analysis based on the same scenarios, of the effects of climate change on European species focusing on 194 European mammals and 500 European plants using a Neural Ensembles modelling approach and two GCM patterns (O'Hanley 2009). This study projected that 13-25 European plant species (16-25 mammals) would incur a climatic range loss of more than $50 \%$ by the 
2080s under the A1B baseline scenario, compared to only 4-5 plants and 4-6 mammals in a stringent mitigation scenario in which global emissions peak in 2016 and are reduced at 5\% thereafter.

We now consider the issue of whether the scenarios we used are feasible. A survey of integrated assessment models by den Elzen et al. (2010) concluded that global long-term emissions reductions rates of up to $3.5 \%$ per year are possible but are less commonly seen in the model studies, which typically try to minimize costs, than lower emission reduction rates. Several other studies have also concluded that higher reduction rates are possible (Climate Change Committee, 2008, O’Neill 2010, UNEP, 2010). Analysis in the AVOID programme using a range of integrated assessment models demonstrated that transitioning from businessas-usual emissions scenarios (which for each model were broadly consistent with SRES A1B) to scenarios that included emissions peaking in 2016 and achieved a 2 degrees $\mathrm{C}$ limit to global warming were technologically possible, but with a broad range of annual 2050 mitigation cost estimates ranging from $-2 \%$ of 2050 GDP (i.e. an economic benefit) to $+9 \%$ of 2050 GDP (Bowen, 2010). Additional analysis in the AVOID programme focused specifically on China and India demonstrated that these two regions could in theory deploy a range of low-carbon technologies which would allow them to achieve per-capita $\mathrm{CO}_{2}$ emissions of around $2 \mathrm{tCO}_{2}$ or less by 2050 , in mitigation scenarios which limited global warming to 2 degrees C, and which included global emissions peaking by 2020 (Gambhir et al, 2011, Gambhir et al, 2012). For China, the annual mitigation cost by 2050 was estimated at about $2 \%$ of China's 2050 GDP, and for India, 1.2-2.4\% of India's 2050 GDP (with the higher level resulting from a scenario in which carbon capture and storage was excluded from available technology options, and biomass availability was limited). Hence we conclude there is evidence that it will be technologically possible to limit warming to $2^{\circ} \mathrm{C}$ above pre-industrial levels but in economic terms could be challenging to do so.

It is possible to make a comparison of the estimated aggregate avoided economic damages from our study with mitigation costs, both from the PAGE2002 model. Upon moving from the A1B baseline to the stringent mitigation scenario in which global emissions peak in 2016 and are reduced at 5\% thereafter, the mean net present value of avoided damages amounts to US\$57, with a $10-90 \%$ range of US\$ $5-136$ trillion while the mean net present value of abatement costs amounts to \$US 9, with a 10 - 90\% range of US\$ $2-18$ trillion (Fig 4a, b). The mean net present value of net benefits amounts to US\$ 48trillion, with a $10-90 \%$ range 
of US\$ 0 -121 trillion (Fig 4c), Hence, in PAGE2002 the benefits exceeds the costs even for the most stringent mitigation scenario, with $90 \%$ confidence.

In other studies a variety of economic optimization approaches have been used to produce cost-benefit analyses for investment in mitigation of global greenhouse gas emissions, using models such as DICE/RICE, ENVISAGE, MERGE, and FUND (Tol 1999; Nordhaus \& Boyer, 2000; Manne \& Richels, 2005; Nordhaus 2008; Roson \& Mensbrugge 2012). Such cost benefit analysis (CBA) has tended to recommend relatively modest levels of mitigation, but the outcome of cost-benefit analysis is very strongly dependent on subjective assumptions, such as the choice of discount rates, and suitable equity weighting (Schneider, 1997; Ackerman et al., 2009). CBA uses simple equations to represent climate change and its impacts which are inconsistent with the latest understanding of the relationships between emissions and climate change, and between climate change and its impacts (Schneider, 1997; Ackerman et al., 2009, Warren et al 2010, Van Vurren et al 2011,) and the simple equations used produce damage curves with simple shapes that have frequently not been correctly calibrated to match recent scientific understanding, lack the ability to represent complex behaviour, and frequently omit or mis-calibrate regional variation. Whilst these same problems may affect our own PAGE2002 results this is minimized by the probabilistic approach, and we do not conduct an optimization process. The outcome of optimization alters each time new parameter values are available from the literature concerning climate change or its impacts, making the process of optimization unreliable. For this reason, an extremely wide range of results can be produced by adjusting the input parameters. Uncertainties in estimates of the social cost of carbon (SCC), one of the strongest determinants of the outcomes of formal cost-benefit analysis, clearly illustrate the dependence of SCC on climate sensitivity, the shape of the climate change damage function, and the value of the discount rate (Ackermann \& Stanton, 2012, Tol 2009). In contrast, the approach described here is based on a risk assessment of alternative scenarios of the future, including a presentation of uncertainties in outcomes of these scenarios. The methods avoid the inherent problems of optimization, and instead estimate the climate change impacts associated with different global greenhouse gas emissions futures, taking into account the uncertainties in our ability to project climate change and its, where possible, impacts. Thus, in our studies we do not select a global temperature limit from an optimized CBA, but instead recognize that the models are better used to provide one of many strands of evidence that will contribute to decisions on a suitable temperature target level. 
380 It should be noted that optimization based approaches using a high (3\%) discount rate commonly result in 'optimal' global temperature rise of between 2.9 and $3.5^{\circ} \mathrm{C}$ above preindustrial levels (Bosello et al. 2010, Hope 2008, Nordhaus 2008, Nordhaus 2010). These moderate levels of mitigation would allow many of the substantial climate change impacts projected here to persist. However, use of lower discount rates in these same models can lower the optimal global temperature rise to around $2.5^{\circ} \mathrm{C}$ (Bosello et al. 2010). Hence the stringent mitigation scenarios examined here are inconsistent with the outcome of optimization approaches if high discount rates are used in the models and yet might be more consistent with them if low discount rates are used. However, it has been shown that the regional damages associated with a $2^{\circ} \mathrm{C}$ temperature increase simulated with physicallybased impacts models differ very significantly from those produced by aggregate economic estimates produced by the RICE integrated model, which is commonly used in optimization based approaches (ClimateCost 2012) and in particular, very large underestimations of damages in Africa and S. and E. Asia have were found..

The findings of our work are consistent with those of Gosling et al. (2011) which also provides evidence of the need for stringent global action on climate change if significant undesirable impacts are to be avoided. Both the economic and physically based modelling approaches used in this study show that if the goal of a mitigation policy is to maximize the avoidance of climate change impacts in the $21^{\text {st }}$ century. It is also likely that the lower temperatures in the mitigation scenarios reduce other impacts associated with abrupt or irreversible changes in the climate system, such as die-back of Amazon forests or irreversible loss of the major ice sheets. For feasible rates of emission reduction of $2-5 \%$, the date at which global emissions peak (over the range 2016-2030) is more influential, in terms of impacts avoided, than the rate of subsequent emission reductions. The study also makes it clear that even in the presence of very stringent mitigation, climate change impacts will be substantial in many areas and hence significant investment in adaptation will be necessary. In spite of this, climate change impacts under stringent mitigation increase much more slowly with time, allowing a slower and more feasible rate of adaptation to the remaining impacts.

In summary, in spite of the uncertainties in projecting precise values of projected climate change impacts, the AVOID study provides strong quantitative evidence for the need for 
stringent and prompt global mitigation action on greenhouse gas emissions combined with effective adaptation if severe climate change impacts are to be avoided. The findings also highlight the inadequacy of the often-deployed cost-benefit analysis to the questions considered here.

\section{References and Notes:}

Ackerman F, DeCanio SJ, Howarth RB, Sheeran K (2009) Limitations of integrated assessment models of climate change. Climatic Change 95:297-315.

Ackerman, F., and Stanton E.A. (2012) Climate Risks and Carbon Prices: Revising the Social Cost of Carbon. Economics: The Open Access, Open Assessment E-Journal 6 (2012-10)

Arnell N.W., Lowe J.A., Brown S., Gosling S.N., Gottschalk P., Hinkel J., Lloyd-Hughes B., Nicholls R.J., Osborn T.J., Osborne T.M., Rose G.A., Smith P, and Warren R. The impacts of climate change avoided by climate policy: a global assessment. (2013)Nature Climate Change (2013) doi:10.1038/nclimate1793

Challinor, A. J., T. R. Wheeler, J. M. Slingo, P. Q. Craufurd and D. I. F. Grimes (2004). Design and optimisation of a large-area process-based model for annual crops. Agricultural and Forest Meteorology, 124, (1-2) 99-120.

Ciscar J.-C., Igleseias A., Feyen L., Szabo L., Van Regemorter D., Amelung B., Nicholls R., Watkiss P., Christensen O.B., Dankers R., Garotte L., Goodess C.M., Hunt A., Moreno A,Richards J., Sonia A. (2011) Physical and economic consequences of climate change in Europe. PNAS 108, 2678-2683

Climate Change Committee (2008). Building a low-carbon economy: The UK's contribution to tackling climate change. (London).

ClimateCost (2012) Available at http://www.climatecost.cc/

den Elzen, M. G. J., van Vuuren, D. P. \& van Vliet, J. (2010) Postponing emission reductions from 2020 to 2030 increases climate risks and long-term costs. Climatic Change 99, 313-320

Elith, J, Phillips, S.J., Hastie, T. Dudik, M., Chee, Y.E., Yates, C.J. (2010). A statistical explanation of MaxEnt for ecologists. Diversity Distrib 17, 43-57

Gambhir et al (2011) China's energy technology options to 2050 (AV/WS2/D1/R26) available at www.avoid.uk.net

Gambhir et al (2012) India's CO2 emissions pathway to 2050 (AV/WS2/D1/R26 R4) available at www.avoid.uk.net)

Good, P., Caesar, J., Bernie, D., Lowe, J.A., van der Linden, P., Gosling, S.N., Warren, R, et al. 2011 A review of recent developments in climate change science. Part 1. Understanding of future change in the large scale climate system. Progress in Physical Geography 35, 281296 DOI10.1177/0309133311407651 
Gosling, S.N. and Arnell, N.W. (2011) Simulating current global river runoff with a global hydrological model: model revisions, validation, and sensitivity analysis. Hydrological Processes, $25,1129-1145$

Gosling SN, Warren R, Arnell NW, Good P, Caesar J, Bernie D, Lowe JA, van der Linden P, O'Hanley JR, Smith SM (2011) A review of recent developments in climate change science. Part II: the global-scale impacts of climate change. Progress in Physical Geography 35: 443-464. doi: 10.1177/0309133311407650

Hinkel, J., Klein, R.J.T. (2009.) Integrating knowledge to assess coastal vulnerability to sealevel rise: The development of the DIVA tool. Global Environmental Change. 19:384-395

Hope C (2008) Discount rates, equity weights and the social cost of carbon. Energy Economics 30:1011-1019.

Hope, Chris W. 2008b. "Optimal Carbon Emissions and the Social Cost of Carbon over Time under Uncertainty." Integrated Assessment Journal, 8(1): 107-122.

Hougton J.T. et al. (Eds.), 2001. Climate change 2001: the physical science basis. Contribution of Working Group I to the Fourth Assessment Report of the Intergovernmental Panel on Climate Change (Cambridge University Press, Cambridge, UK).

Huntingford, C., Lowe J.A., Gohar L.K., Bowerman N.H.A., Allen M.R., Raper S.C.B., Smith S.M. (2010) The link between a global $2^{\circ} \mathrm{C}$ warming threshold and emissions in years 2020, 2050 and beyond. Environ. Res. Lett. 7 (2012) 014039

Johns, T. C.; Royer, J. -F.; Hoeschel, I.; et al.Climate change under aggressive mitigation: the ENSEMBLES multi-model experiment. CLIMATE DYNAMICS Volume: 37 Issue: 9-10 Pages: 1975-2003 DOI: 10.1007/s00382-011-1005-5 (2011)

Lowe J.A.,Hewitt C.D., van Vuuren D.P., and Johns T.C. (2009a) New study for climate modelling, analyses and scenarios, Eos 90, 181-18.

Lowe J.A. , Huntingford C., Raper S.C.B., Jones C.D., Liddicoat S.K. and Gohar L.K. (2009b), How difficult is it to recover from dangerous levels of global warming? Environ. Res. Lett. 4014012

Meehl, G. A. et al. The WCRP CMIP3 multimodel dataset - A new era in climate change research. Bulletin of the American Meteorological Society 88, 1383-+ (2007)

Manne A, Richels R (1995) MERGE - A Model for Evaluating Regional and Global Effects of GHG Reduction Policies. Energy Policy 23:17 - 34.

Moss, R.H., et al. 2010. The next generation of scenarios for climate change research and assessment. Nature 463: 747-756 doi:10.1038/nature08823

Nakicenovich N. et al. (2000) Special Report on Emission Scenarios (Cambridge University Press, Cambridge, UK,

Nordhaus, W.D. and Boyer,M., Warming the world: economic models of global warming (MIT, Cambridge, USA, 2000).

Nordhaus W.D. (2008) A question of balance: weighing the options on global warming policies. Yale University Press. 
Nordhaus, W.D. (2010) Economic aspects of global warming in a post-Copenhagen environment. PNAS 107 (26) 11721-11726

O'Hanley JR (2009) NeuralEnsembles: a neural network based ensemble forecasting program for habitat and bioclimatic suitability analysis. Ecography 32, 89-93

O’Neill, B.C., K. Riahi, and I. Keppo, 2010: Mitigation implications of midcentury targets that preserve long-term climate policy options. Proceedings of the National Academy of Sciences, 107(3), 1011-1016

Ramankutty, N., Foley, J.A., Norman, J., and McSweeney, K. (2009) The global distribution of cultivable lands: current patterns and sensitivity to possible climate change. Global Ecology and Biogeography 11, 377-392

Schneider S (1997) Integrated assessment modelling of global climate change: Transparent rational tool for policy making or opaque screen for hiding value-laden assumptions? . Environmental Monitoring Assessment 2:229-249.

Solomon S. et al. (Eds.), 2007. Climate change 2007: the physical science basis. Contribution of Working Group I to the Fourth Assessment Report of the Intergovernmental Panel on Climate Change (Cambridge University Press, Cambridge, UK).

Smith JB, Schneider SH, Oppenheimer M, et al. (2009) Assessing dangerous climate change through an update of the Intergovernmental Panel on Climate Change (IPCC) 'reasons for concern'. Proceedings of the National Academy of Sciences of the United States of America 106: 4133-4137.

Tol RSJ (1999) Spatial and temporal efficiency in climate policy: applications of FUND. . Environmental and Resource Economics 14:33-49.

Tol, R.S.J. (2009), 'The Economic Effects of Climate Change', Journal of Economic Perspectives, 23, (2), 29-51.

UNEP (2010) The Emissions Gap Report: Are the Copenhagen Pledges sufficient to limit global warming to $2^{\circ} \mathrm{C}$ or $1.5^{\circ} \mathrm{C}$ ?, November 2010 .

Van Vuuren, D., Lowe, J., Stehfest, E., Gohar, L., Hof, A.F., Hope, C., Warren, R., Meinshausen, M., and Plattner, G.-K. 2011. How well do integrated models simulate climate change? Climatic Change.104, 255-285.

Warren, R., Mastrandrea, M., Hope, C., and Hof, A. 2010. Variation in the climatic response of integrated models. Climatic Change 102 (3-4): 671-685

Warren R, Yu RMS, Osborn TJ, Santos SD (2012) European drought regimes under mitigated and unmitigated climate change: application of the Community Integrated Assessment System (CIAS). Climate Research 51:105-U137.

Warren, R., VanDerWal, J., Price, J., Welbergen, J.A, Atkinson, I., Ramirez-Villegas, J., Osborn, T.J., Jarvis, A., Shoo, L.P., Williams, S.E., Lowe, J. Quantifying the benefit of early mitigation in avoiding biodiversity loss. (in press).

Wigley TML, Raper SCB (2001) Interpretation of high projections for global-mean warming. 
Science 293:451-454.

Acknowledgments:

568 This work was supported by the AVOID programme (DECC and Defra) under contract 569 GA0215. 
Figure 1a Cumulative probability of constraining global temperature outcomes in the AVOID scenarios, showing the probability of constraining global temperature rise below various thresholds

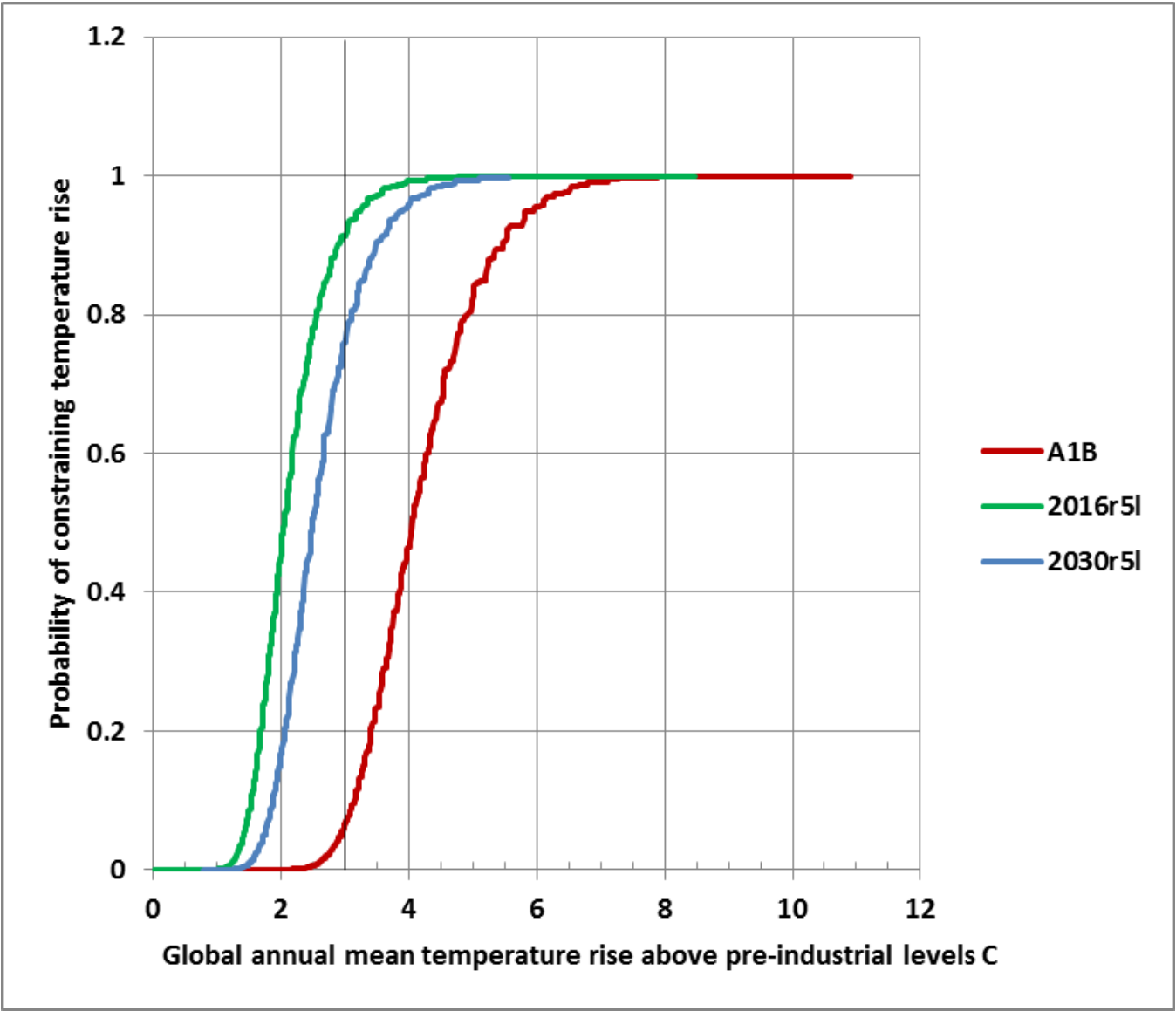

Figure 1b The 10, 50 and 90 percentile outcomes of global temperature rise in the AVOID scenarios.

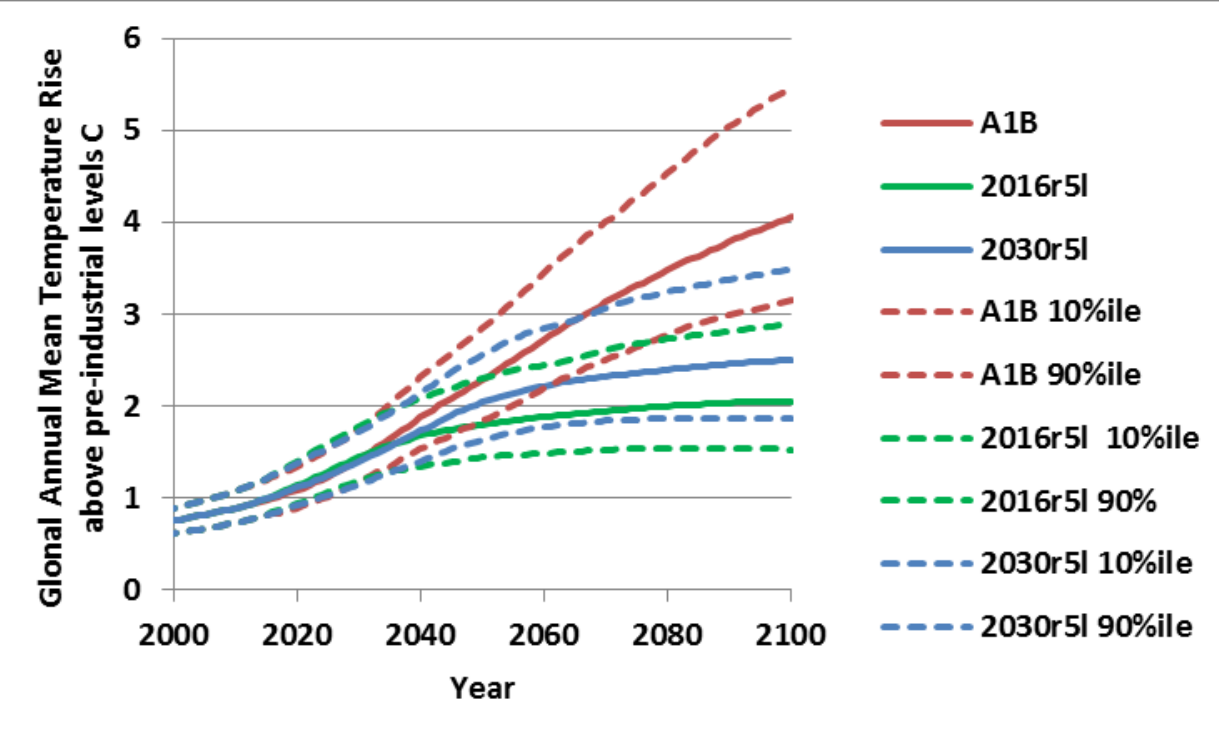




\section{Figure 2a}

582 Percentage of climate change impacts avoided in the 2100 in various sectors upon moving from an unmitigated A1B baseline to three of our mitigation scenarios in which emissions are reduced at 5\% annually after peaking globally in 2016 (red bars, scenario 2016R5L), reduced at $2 \%$ annually after peaking globally in 2016 (pink bars) or reduced at 5\% annually after peaking in 2030 (orange bars, scenario 2030R5L). Avoided benefits are shown in shades of blue for the same three scenarios. The total economic damages are produced by the PAGE model and refer to the sum of market and non-market impacts (and actually refer to impacts in the 2080s). Error bars represent $10 \%$ and $90 \%$ estimates for all sources of uncertainty in climate projection and impact estimation (for PAGE model) or the effect of use of a range of downscaling patterns corresponding to the emulation of seven alternative global circulation models (for physically based impacts models).

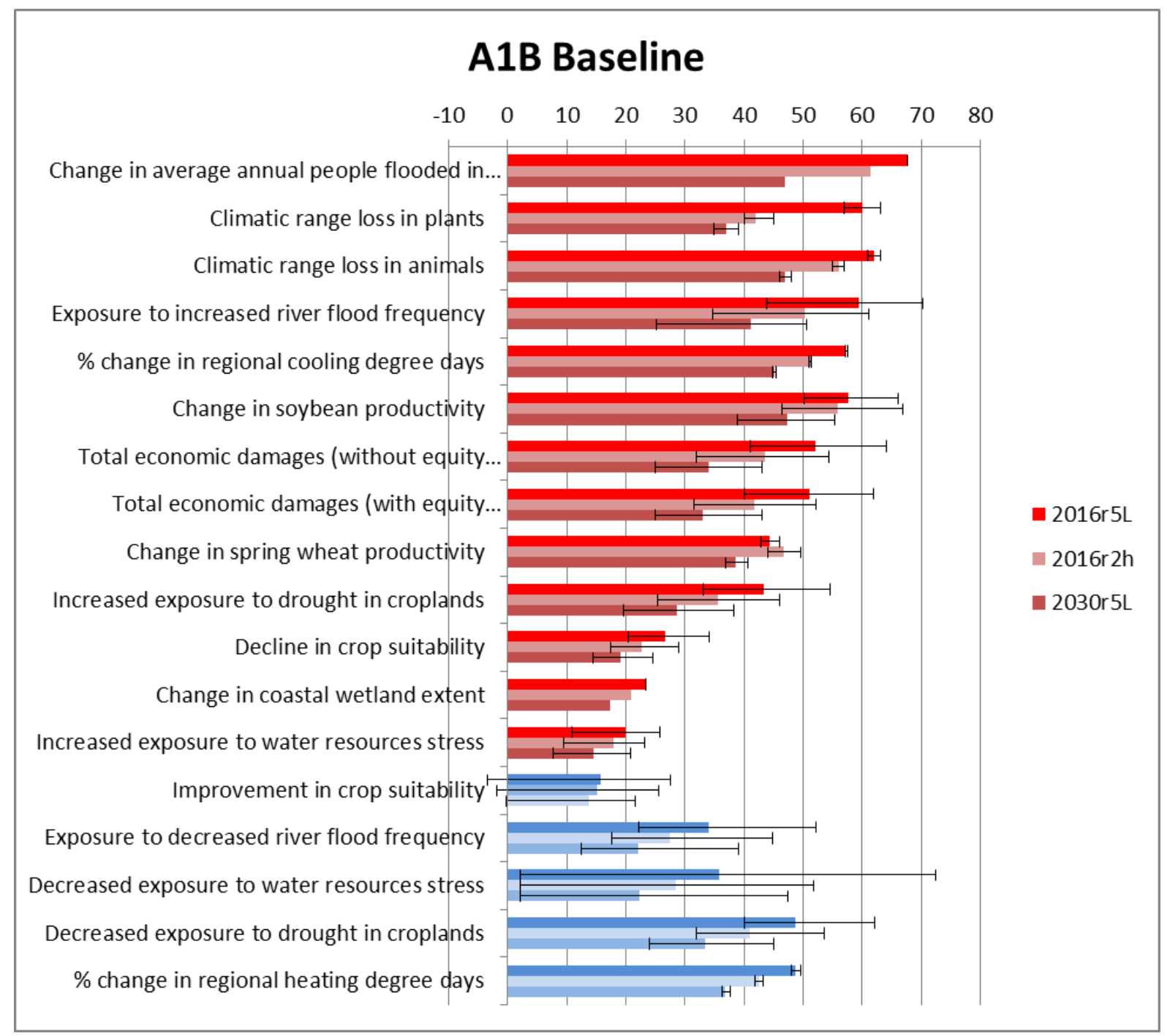




\section{$605 \quad$ Figure 2b}

606 As Figure 2b, but for A1FI (for a smaller selection of metrics than Figure 2a).

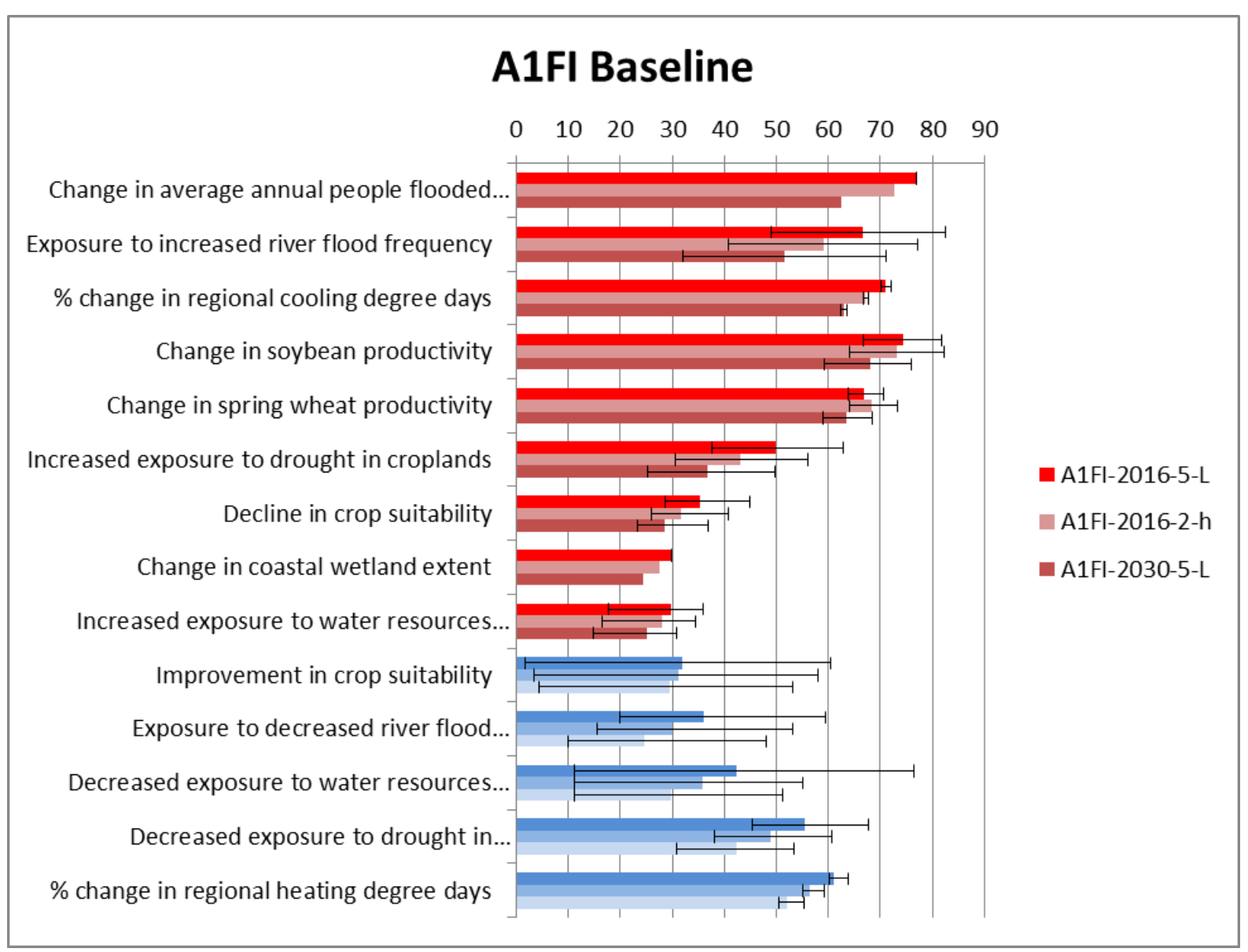


611 Figure 3a, b Probability distribution of estimated aggregate economic climate change 612 impacts in the 2080s in an unmitigated A1B baseline as produced by PAGE model.

613 Estimates refer to the sum of market and non-market impacts and encompass uncertainties in 614 both climate change modelling and in estimation of damages. Fig 3a refers to equity615 weighted estimates and Fig $3 \mathrm{~b}$ to un-weighted estimates.

616 a. Impacts in 2080, A1B scenario, weighted.

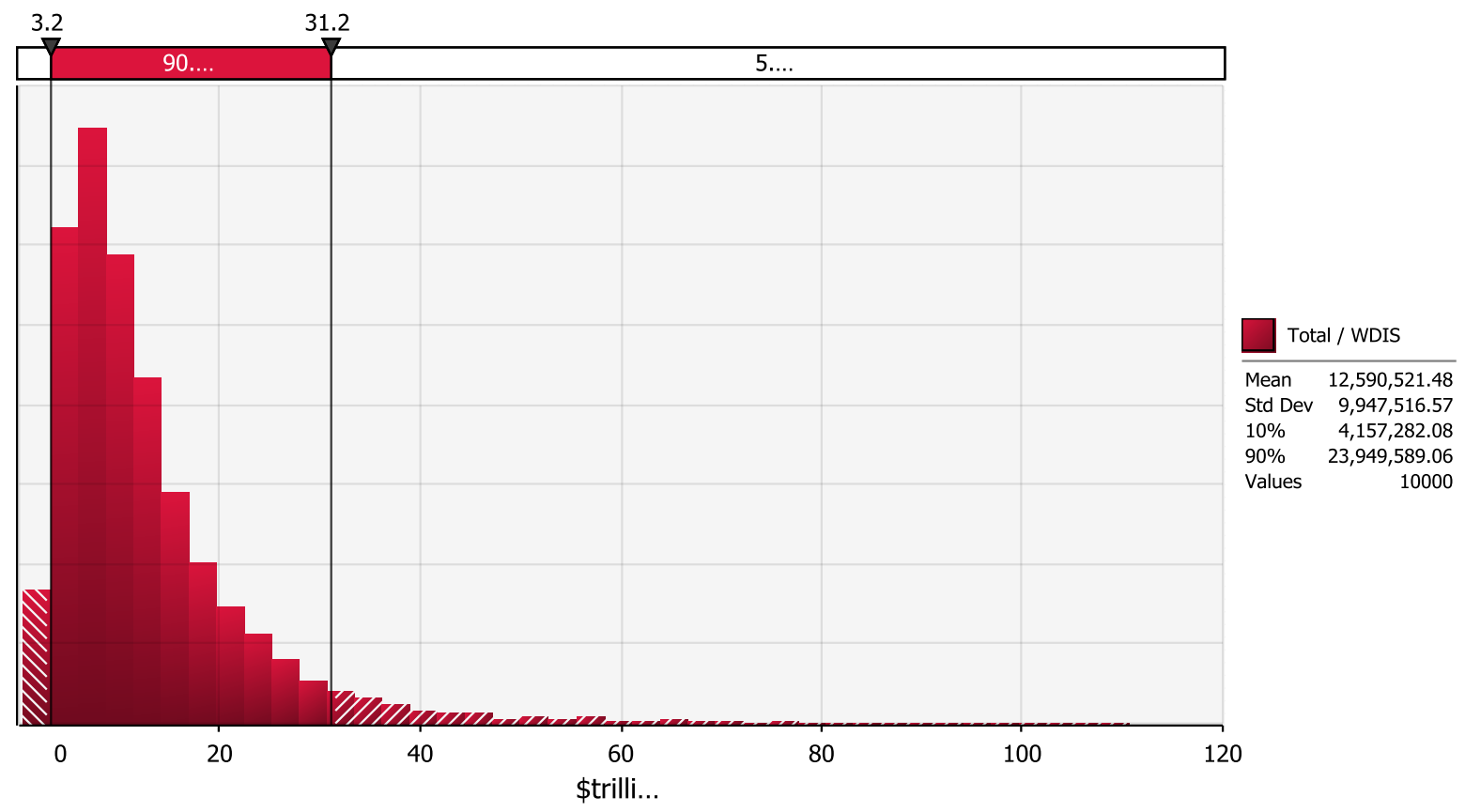


b. Impacts in 2080, A1B scenario, unweighted.

Total / W...

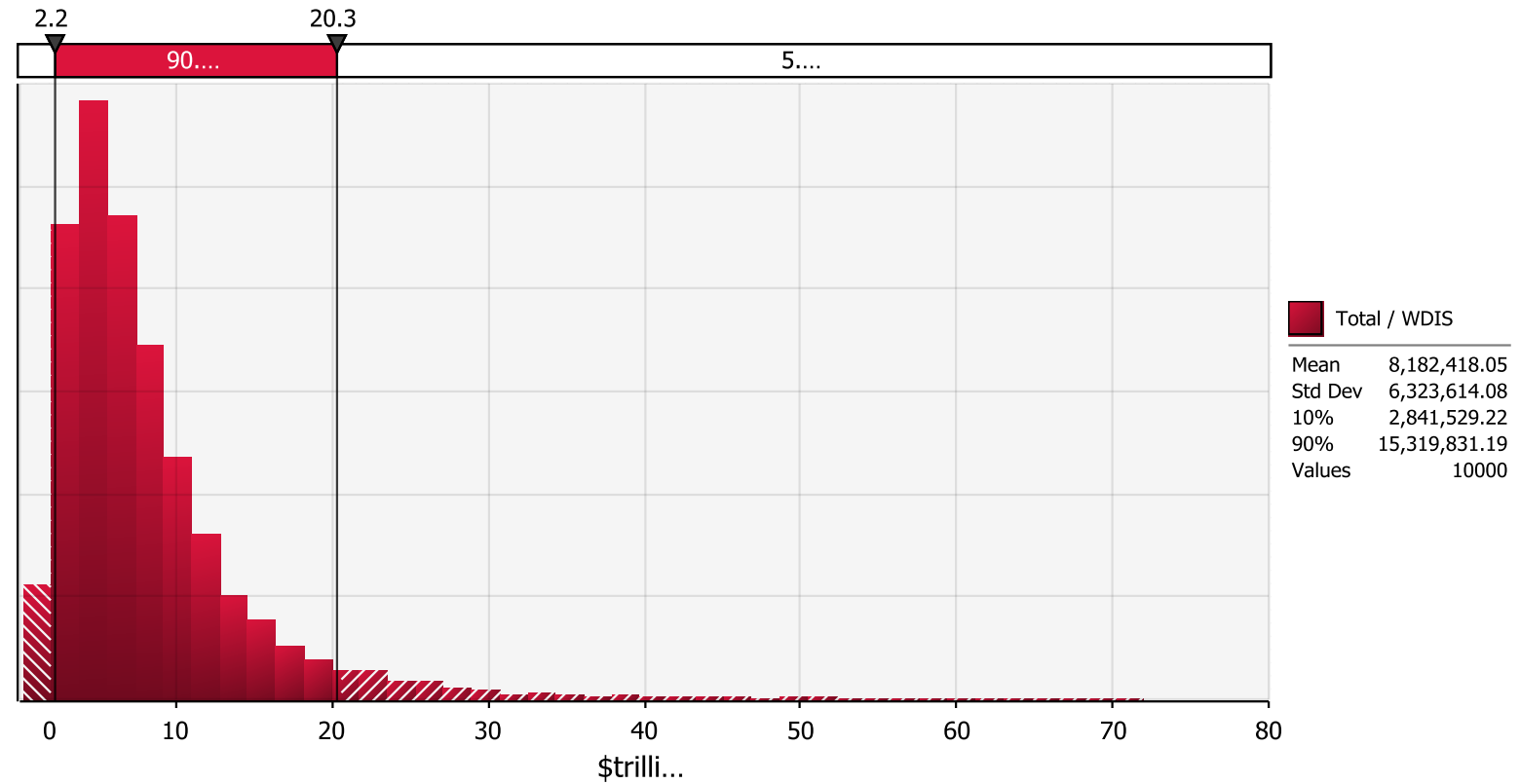

621

622

623

624

625 


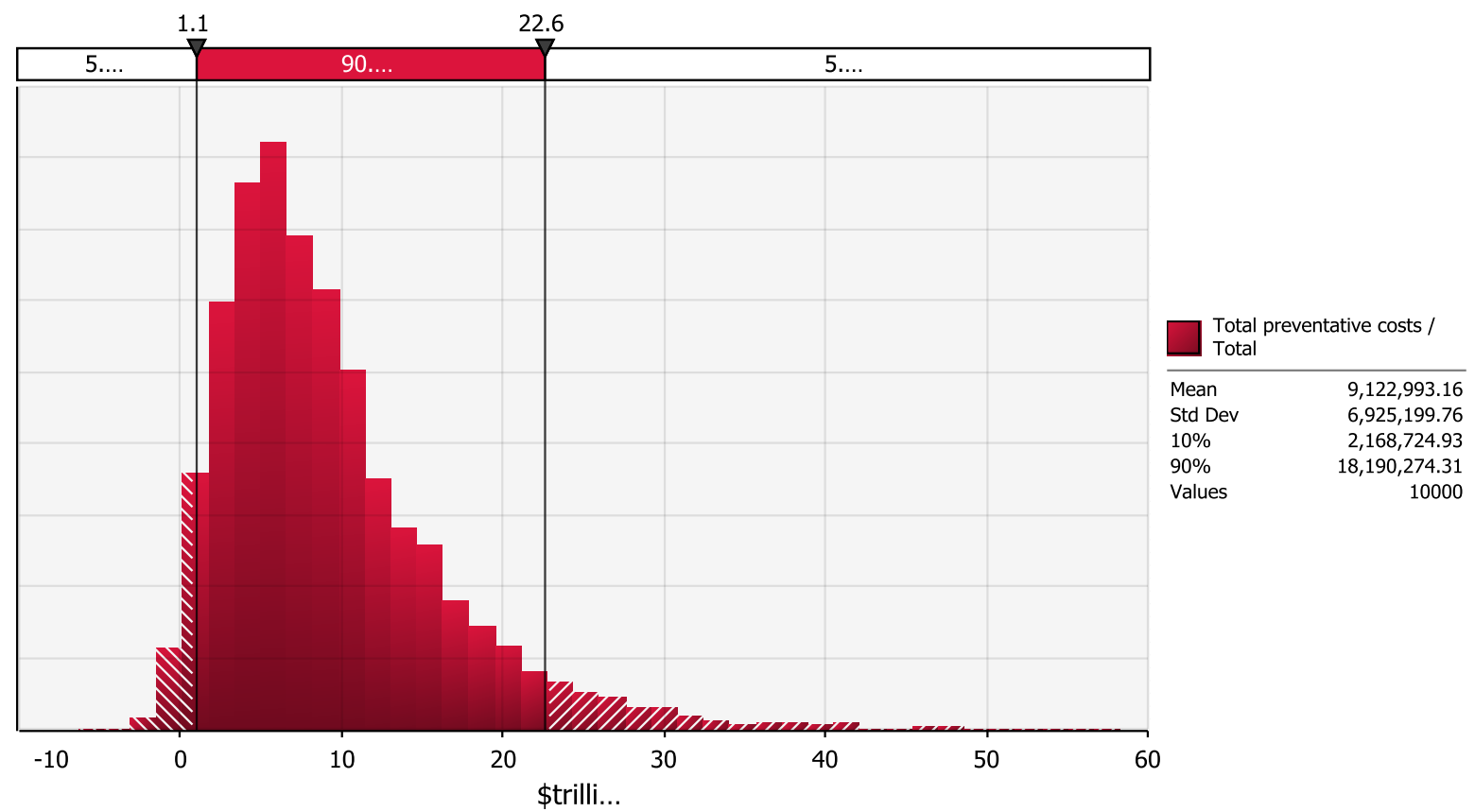

Figure 4a Net present value of abatement costs from 2000 to 2200 in the PAGE2002 model upon moving from a baseline A1B scenario to a mitigation scenario in which global emissions peak in 2016 and decline at $5 \%$ annually thereafter

632

633

634

635

636 


\section{Figure 4b}

640 Net present value of avoided impacts from 2000 to 2200 in the PAGE2002 model upon moving from a baseline A1B scenario to a mitigation scenario in which global emissions peak in 2016 and decline at $5 \%$ annually thereafter

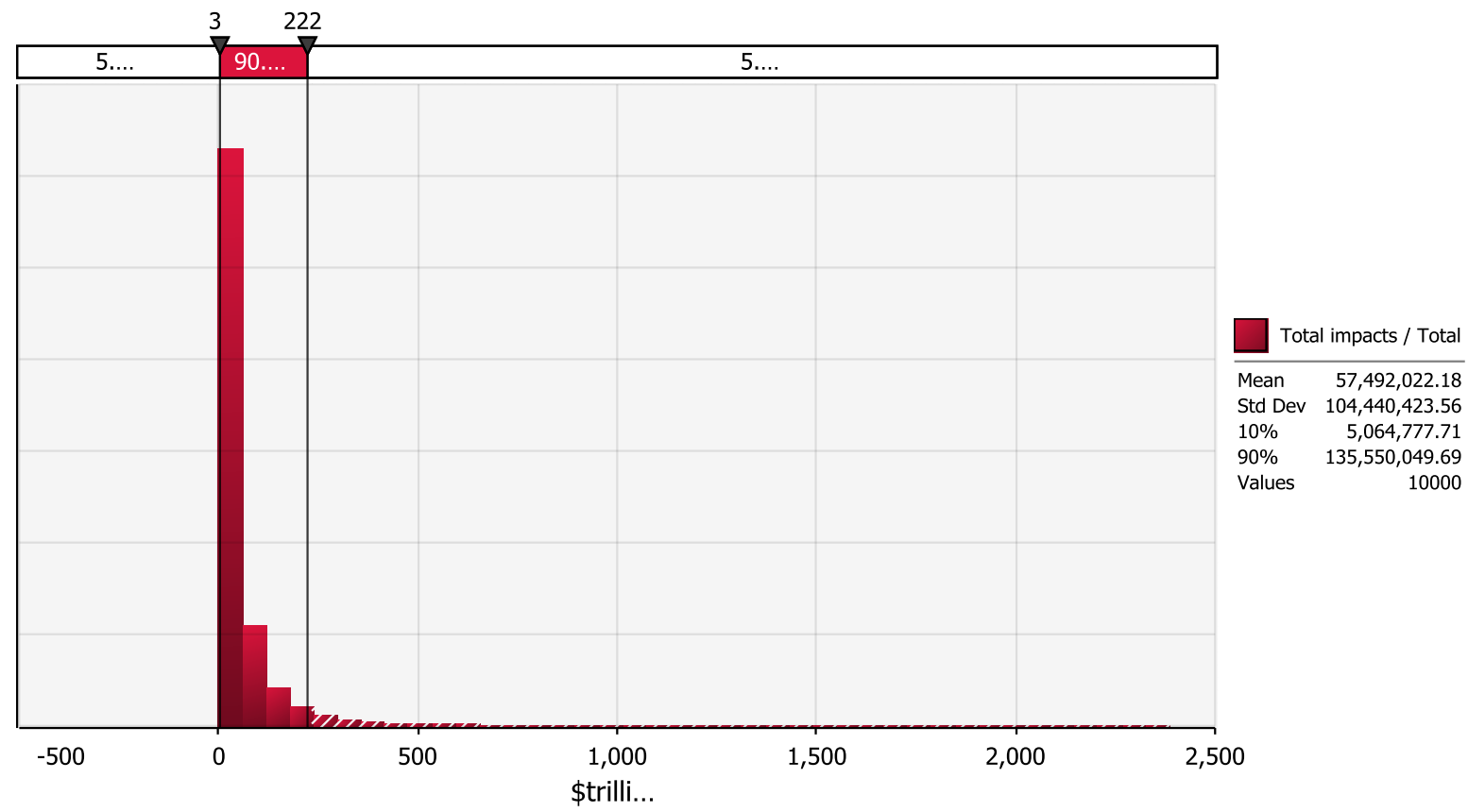


668 Figure 4c Net present value of net benefits (i.e. - avoided impacts minus abatement costs) 669 from 2000 to 2200 in the PAGE2002 model upon moving from a baseline A1B scenario to a 670 mitigation scenario in which global emissions peak in 2016 and decline at $5 \%$ annually 671 thereafter

672

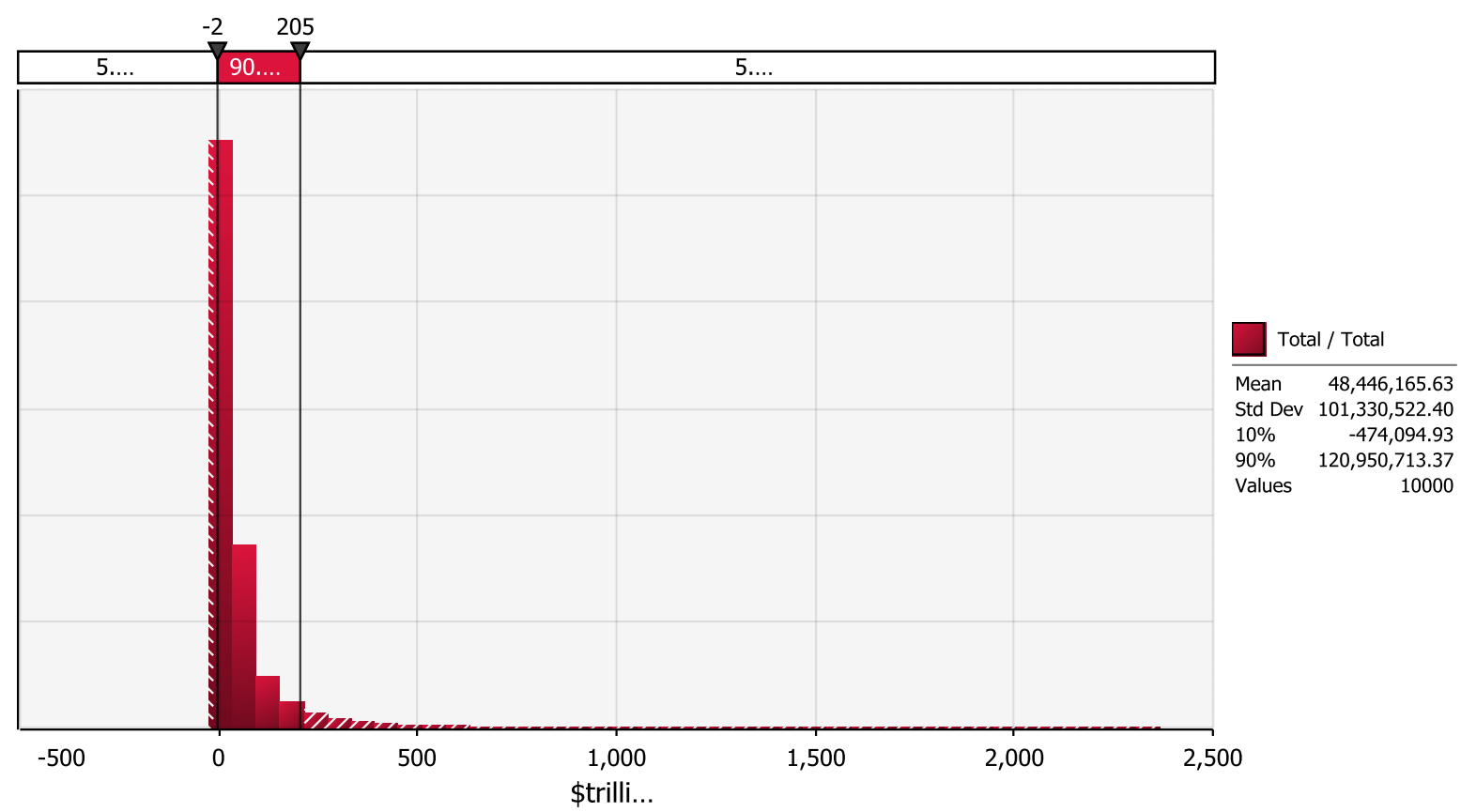

